\title{
Deposition of silver nanoparticles on titanium surface for antibacterial effect
}

\author{
This article was published in the following Dove Press journal: \\ International Journal of Nanomedicine \\ 7 April 2010 \\ Number of times this article has been viewed
}

\author{
Liao Juan' \\ Zhu Zhimin ${ }^{3}$ \\ Mo Anchun ${ }^{1,2}$ \\ Li Lei' \\ Zhang Jingchao' \\ 'State Key Laboratory of Oral \\ Diseases, Sichuan University, Chengdu \\ 6I004I, PR China; ${ }^{2}$ Department \\ of Dental Implant, West China \\ Stomatology Hospital, Sichuan \\ University, Chengdu 6I004I, PR China; \\ ${ }^{3}$ Department of Prosthodontics, West \\ China Stomatology Hospital, Sichuan \\ University, Chengdu 61004I, PR China
}

Correspondence: Mo Anchun West China College of Stomatology, Sichuan University, No. 17, 3rd section, Renmin Road, Chengdu, China, 61004I

Tel +8628 8550357।

$\mathrm{Fax}+862885582167$

Email moanchun@I63.com

\begin{abstract}
Microbial colonization on implanted devices and biofilm formation is a recurrent complication in implant surgery and may result in loss of implants. The aim of this study was to deposit silver nanoparticles on a titanium surface to obtain antibacterial properties. In the present study, we prepared a silver nanoparticle-modified titanium (Ti-nAg) surface using silanization method. The morphology and chemical components of the Ti-nAg surface were characterized by scanning electron microscopy (SEM) equipped with energy-dispersive spectroscopy (EDS). Two species of bacteria, Staphylococcus aureus and Escherichia coli, were utilized to test the antibacterial effect of the Ti-nAg treated surface. The SEM examination revealed that a small quantity of silver nanoparticles was sparsely deposited on the titanium surface. The diameter of these nanoparticles ranged from ten to several hundred $\mathrm{nm}$. EDS analyses revealed that there was $4.26 \%$ of Ag present on the surface. After a 24-hour incubation, 94\% of Staphylococcus aureus and over $95 \%$ of Escherichia coli had been killed on the Ti-nAg surface, and the SEM examination of anti-adhesive efficacy test showed that there were less bacteria attached to Ti-nAg surface than to a control surface of untreated Titanium. These data suggest that silver nanoparticle-modified titanium is a promising material with an antibacterial property that may be used as an implantable biomaterial.
\end{abstract}

Keywords: nano-silver, titanium, antibacterial activity, silanization method

\section{Introduction}

Implanted devices such as artificial hip or knee joints, and dental implants are suitable substrates for microbial colonization and biofilm formation, which is a recurrent complication in implant surgery. ${ }^{1}$ Because of excellent resistance to corrosion and great biocompatibility, titanium has been widely used as an implantable biomaterial for devices of dental implants, fracture fixation, joint replacement, vertebral column orthopedic and percutaneous-transmucosal surgery. Multiple factors affect the outcome of orthopedic and dental implants, including osseointegration of boneimplant and the degree of aggregation of bacteria surrounding the implants. Previous studies have revealed that inflammatory diseases around dental implants may cause peri-implantitis and loss of supporting bone, which is associated with the reduction of long-term "survival" of implants. ${ }^{2}$ It is known that microorganisms and host cells compete for the substrate in a process called "race for the surface". ${ }^{3}$ The avoidance of attached microorganisms on the surfaces of implanted devices is best practice for the survivability of any implant. However, infected implants and their consequent loosening is most common in titanium devices and this is still a challenge in clinical practice. In the past decades, many strategies have been developed to prevent or reduce 
bacterial colonization of the surface of titanium devices. Such strategies include: surface modifications to reduce concavity, such as polishing; and modification of the physical properties of the device such as surface-free energy.,5

Silver is well known for its antimicrobial properties and has been used for many years in the medical field for antimicrobial purposes. ${ }^{6}$ Silver impregnated hydroxyapatite film on an alumina substrate has shown excellent antibacterial properties against both Gram-positive and Gram-negative bacteria. ${ }^{7}$ It has also been reported that silver-zeolite inhibits the growth of bacteria under anaerobic conditions. ${ }^{8,9}$ In addition to this, it has been shown that silver is capable of preventing human immunodeficiency virus (HIV) from binding to host cells. ${ }^{10,11}$ Consequently it has been suggested that silver inhibits bacterial invasion by several mechanisms. Because silver nanoparticles possess a large total surface area available for bacterial interaction they exhibit a stronger antibacterial effect than regular metallic silver. ${ }^{12}$ As a consequence the incorporation of silver nanoparticles with other materials, to increase an antibacterial capability is currently the subject of intense study and several methods have been developed such as: silver-doped hydroxyapatite; ${ }^{13}$ polymer-silver nanoparticles, ${ }^{14}$ and silver nanoparticles on $\mathrm{TiO}_{2} \cdot{ }^{15}$ In light of the above findings, we hypothesized that a titanium surface upon which silver nanoparticles adhere could exhibit excellent antibacterial properties. To test this hypothesis, we prepared a silver nanoparticle-modified titanium (Ti-nAg) surface using silanization method, ${ }^{16}$ and determined the size, shape and distribution of the silver nanoparticles with scanning electron microscopy (SEM) equipped with energydispersive spectroscopy (EDS). Furthermore, we examined the antibacterial and anti-adhesive properties using three well established microbiological assays.

\section{Materials and methods \\ Materials}

Silver nitrate $\left(\mathrm{AgNO}_{3}\right.$, purity, 99.9\%), concentrated sulfuric acid (purity, 98\%), trisodium citrate (purity, 99\%), hydrogen peroxide, sodium borohydride $\left(\mathrm{NaBH}_{4}\right.$, purity, $\left.98 \%\right)$, acetone 3-(aminopropyl) triethoxysilane (APS, purity, 99.5\%), and sodium hydroxide (purity, $99.99 \%$ ) were used in the present study. All of above reagents were obtained from Sigma-Aldrich (St Louis, MO, USA). Titanium sheets (mass ratio 99\%, 12 mm diameter) were purchased from BaoTi (Xian, China).

\section{Methods}

\section{The preparation of titanium plate}

Titanium coupons were ground into the shape of a plate using 1200 grit, then polished using $0.3-\mu \mathrm{m}$ aluminum before being ultrasonically cleaned with acetone and distilled water. The polished titanium surface was first etched with "piranha solution" for 1.5 hours at $75^{\circ} \mathrm{C}$ (piranha solution: $3: 730 \%$ hydrogen peroxide/concentrated sulfuric acid). The titanium coupons were then rinsed extensively with deionized (DI) water and dried in a stream of dry nitrogen $\left(\mathrm{N}_{2}\right)$. The cleaned titanium coupons was silanized using a $2 \%$ APS solution for 1.5 hours, ${ }^{17}$ followed by extensive rinsing with ethanol and water. Following this the coupons were sonicated in ethanol for 30 seconds. Finally, the APS-treated titanium coupons were again rinsed with water and dried in a stream of $\mathrm{N}_{2}$.

\section{Deposition of silver nanoparticles onto titanium surface}

Firstly $20 \mathrm{~mL}$ of an aqueous solution of silver nitrate; with a final concentration of $0.25 \mathrm{mM}$, and $0.25 \mathrm{mM}$ trisodium citrate was prepared. While stirring vigorously, $0.6 \mathrm{~mL}$ of $10 \mathrm{mM} \mathrm{NaBH}_{4}$ was added to the solution. ${ }^{18}$ Following this the silver nanoparticles were deposited onto the APStreated titanium coupons by a 3-hour incubation in the silver nanoparticle solution. The resultant coupons was then rinsed with DI water and dried in a stream of $\mathrm{N}_{2} \cdot{ }^{19}$

\section{Characterization of the silver nanoparticles on titanium surface}

The morphology and composition of the Ti-nAg surface of the titanium coupons was characterized using an SEM (HITACHI S-4800, Tokyo, Japan) equipped with EDS (alpha ray spectrometer, Oxford, UK).

\section{Antibacterial tests}

The antimicrobial activity of the Ti-nAg surface was tested against the Gram-negative bacteria Escherichia coli (ATCC 8099, Rockville MD, USA) and Gram-positive Staphylococcus aureus (ATCC 6538, Rockville MD, USA). Zones of inhibition $(\mathrm{ZoI})$ tests were carried out to determine the extent of silver ion release from the Ti-nAg surface. A film applicator coating (FAC) assay was used to test the antimicrobial effect by directly incubating microbial cells on Ti-nAg or polished titanium (Ti-polished, control titanium) surfaces. In the ZoI test, the concentration of Staphylococcus aureus was adjusted to $1 \times 10^{6}$ colony-forming units (CFUs)/mL and spread evenly on Luria-Bertani medium agar plates. Ti-nAg and the nonmodified control titanium coupons were placed on the above prepared agar plates separately. The plates were incubated at $37^{\circ} \mathrm{C}$ in an aerobic petri dish for 24 hours and photographed to record the results. In the FAC assay the concentration of each bacterial strain was adjusted to $1 \times 10^{4}$ cells $/ \mathrm{mL}$ in phosphate buffer solution (PBS: $\mathrm{NaCl} 137 \mathrm{mmol} / \mathrm{L}, \mathrm{KCl} 2.7 \mathrm{mmol} / \mathrm{L}$, 
$\mathrm{Na}_{2} \mathrm{HPO}_{4} 4.3 \mathrm{mmol} / \mathrm{L}, \mathrm{KH}_{2} \mathrm{PO}_{4} 1.4 \mathrm{mmol} / \mathrm{L}$ ) and Luria Bertani Medium (tryptone, yeast extract, $\mathrm{NaCl}$ ). The titanium coupons were then put on these culture plates and kept in wet boxes. Then $10 \mu \mathrm{L}$ bacterial suspension was applied to the Ti-nAg and the titanium control coupons, respectively. Following incubation at $37^{\circ} \mathrm{C}$ in an aerobic petri dish for 24 hours, the bacterial suspensions on the coupons were then transferred separately into tubes containing $10 \mathrm{~mL}$ of sterilized PBS, followed by vigorous vortex mixing for 5 minutes. Following this $10 \mu \mathrm{l}$ of bacterial solutions from the mixtures were then spread on Luria Bertani medium broth-agar plates. The plates were incubated aerobically for 24 hours. The viable cells on each of the plates were counted by quantifying the CFUs. Each of the groups were respectively compared, using an independent Student's t-test. For all statistical analyses, the probability of type I errors less than or equal to 0.05 was considered as statistically significant. Each test was run in triplicate and repeated on three separate occasions. The antibacterial effect in each group was calculated as a bactericidal ratio which was calculated as follows:

$$
\begin{aligned}
\text { Bactericidal ratio }(\%)= & {[(\mathrm{CFU} \text { of } \mathrm{CG}-\mathrm{CFU} \text { of } \mathrm{EG}) / \mathrm{CFU}} \\
& \text { of } \mathrm{CG}] \times 100 \%,
\end{aligned}
$$

CFU represents colony-forming unit; $\mathrm{CG}$ is the Tipolished coupons (control group); and EG is Ti-nAg coupons (experimental group).

\section{Anti-adhesive test}

The anti-adhesive activity of the Ti-nAg coupons towards Staphylococcus aureus and Escherichia coli was qualitatively evaluated by SEM. Ti-nAg and the control titanium coupons were immersed in $10 \mathrm{~mL}$ of the bacterial suspensions, which contained $1 \times 10^{8}$ cells $/ \mathrm{mL}$, cultured in Luria Bertani medium for 24 hours. The loosened and unattached bacteria cells were removed by sinking the plates into sterile PBS. The coupons were subsequently fixed with $2.5 \%$ glutaraldehyde solution for 2 hours at room temperature. After dehydration in an ethanol series $(30 \%, 50 \%, 70 \%, 80 \%, 90 \%$ and $100 \%)$, the ethanol in the plates was removed by soaking in an amyl acetate solution for 1 hour at room temperature. Following this the plates were dried and coated with $8 \mathrm{~nm}$ Au using a sputter coater before being visualized with SEM.

\section{Results and discussion Characterization of silver nanoparticle- modified titanium surface}

During the process of preparing the surfaces one noticeable change was the color of the titanium sheet which became
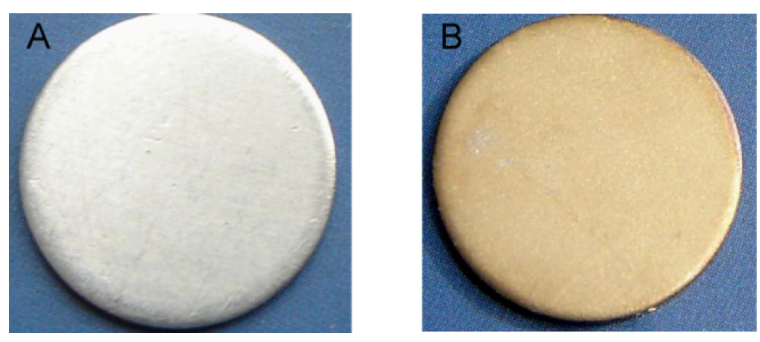

Figure I Photographs show the appearance of Ti-polished $\mathbf{A}$ ) and Ti-nAg B).

gold after it had been etched using the piranha solution and treated with silver nanoparticle solution (Figure 1b). The SEM micrographs showed silver nanoparticles sparsely deposited on the titanium surface, with a diameter of approximately $100 \mathrm{~nm}$. Some silver nanoparticles formed aggregates (Figure $2 \mathrm{a}-\mathrm{d}$ ). In contrast, the surface of the titanium sheet that has been etched by piranha solution, although not treated with the silver nanoparticle solution, showed many nanopores with a diameter of approximately $50 \mathrm{~nm}$, (Figure $2 \mathrm{f}$ ). After the Ti coupons had been polished (Figure 2e) no nanopores were observed. To verify the chemical elements present in the nanoparticles EDS analyses were performed. As shown in Figure 3, whenever the probe detected a silver nanoparticle (Figure 3a), the peak value of titanium reduced and the peak value of Ag increased (Figure 3b). The EDS analyses revealed that the nanoparticles on Ti-nAg surface were Ag and they were $4.26 \%$ Ag (Figure 4, Table 1).

\section{Antimicrobial and anti-adhesive properties}

The antibacterial mechanism of Ti-nAg surface is attributable to the presence of the silver nanoparticles and released silver ions. The silver nanoparticles show efficient antimicrobial property due to their extremely large surface area, which provides an effective contact with microorganisms. The nanoparticles release silver ions in aqueous solution, which enhances their bactericidal activity. ${ }^{20}$ It has been reported that $\mathrm{Ag}$ ions bind strongly to electron donor groups present in biological molecules containing sulfur, oxygen or nitrogen. ${ }^{21}$ Since Staphylococcus aureus and the Escherichia coli have been reported to be the most common pathogens in biomaterial-associated infections, ${ }^{22}$ these two bacteria were deemed appropriate for testing the antibacterial properties of the Ti-nAg surface. There are at least two mechanisms of inhibiting the formation of microbial plaque. The first is to inhibit the initial adhesion of bacteria, and the second is to inhibit the colonization of bacteria. In this study, we adopted two methods (ZoI and FAC tests) to determine antibacterial 

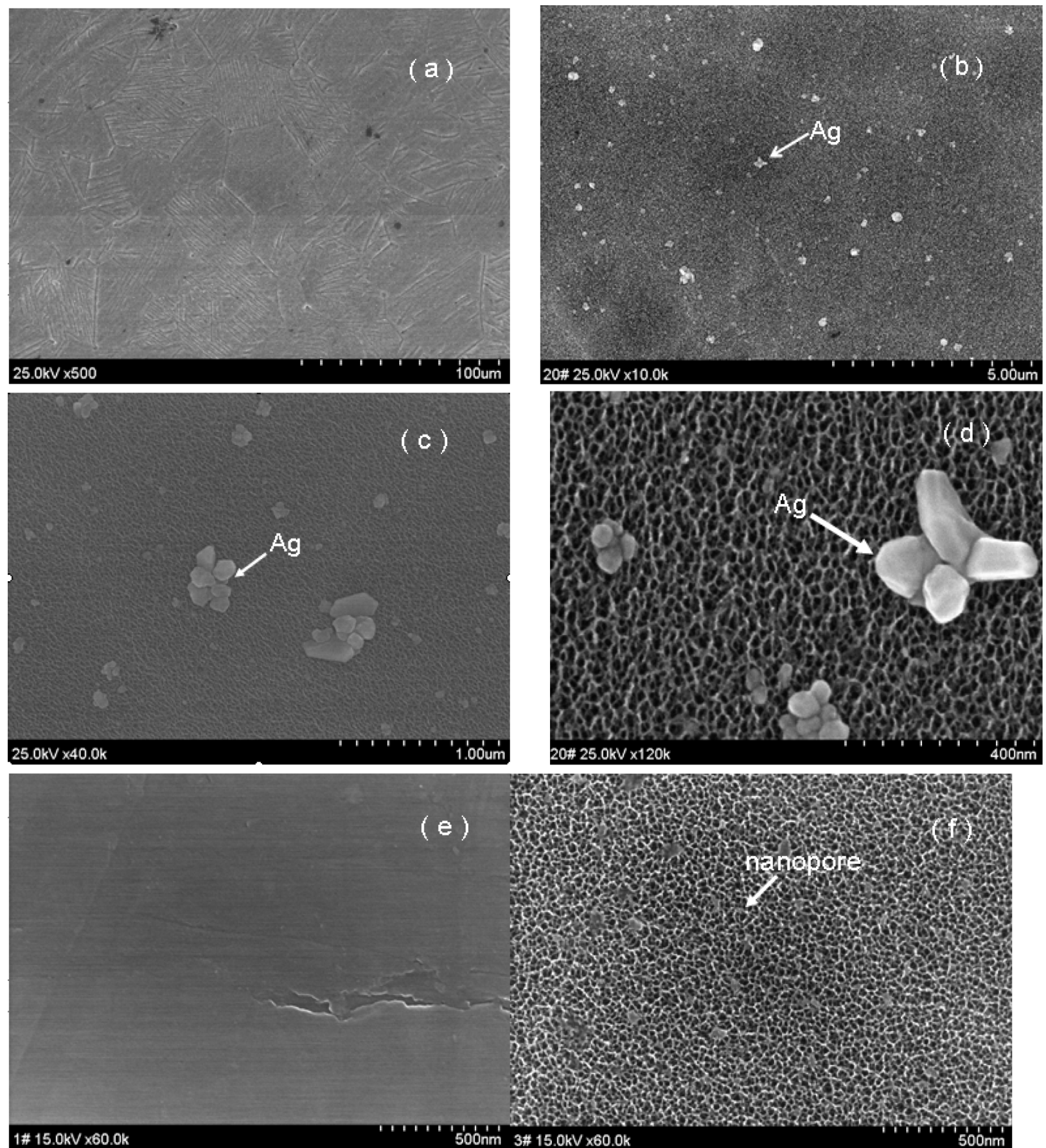

e)
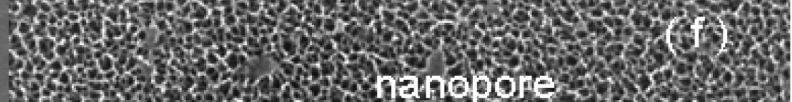

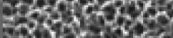
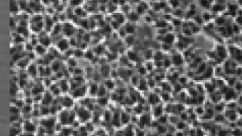

Aforso

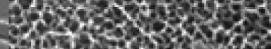

nye wh

79050

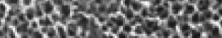

303000.

38

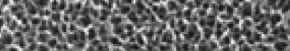

$3 \# 15.0 \mathrm{kV} \times 60.0 \mathrm{k}$

Figure 2 Morphological characterization of Ti-Ag surface. SEM micrographs show Ti-nAg surface at different magnifications: (a) $\times 500$; (b) $\times 10000$; (c) $\times 40000$; and (d) $\times 120000$. Ti-polished surface $(e)$ magnification $\times 60000$, and titanium surface after etched by piranha solution but before treated with silver solution $(f)$ magnification: $\times 60000$. Notes: (working distance: $15000 \mu \mathrm{m}$; accelerating voltages: $25 \mathrm{KV}$ ).

Abbreviation: SEM, scanning electron microscopy.

activities and one test for anti-adhesive activities of the Ti-nAg surface.

As shown in Figure 4, there was no zone of inhibition observed around either the Ti-nAg plate (Figure 5a) or the Ti-polished plate (Figure 5b). Since the ZoI test was based on the leaching of silver ions from the surface, the inhibition of the bacterial growth depends on a sufficient concentration of silver ions in the surrounding aqueous environment. However, our SEM examination revealed that only a small percentage of the modified titanium surface was covered by silver nanoparticles, which accounted for just $4.26 \%$ of the surface chemical elements. In addition, because the elemental 

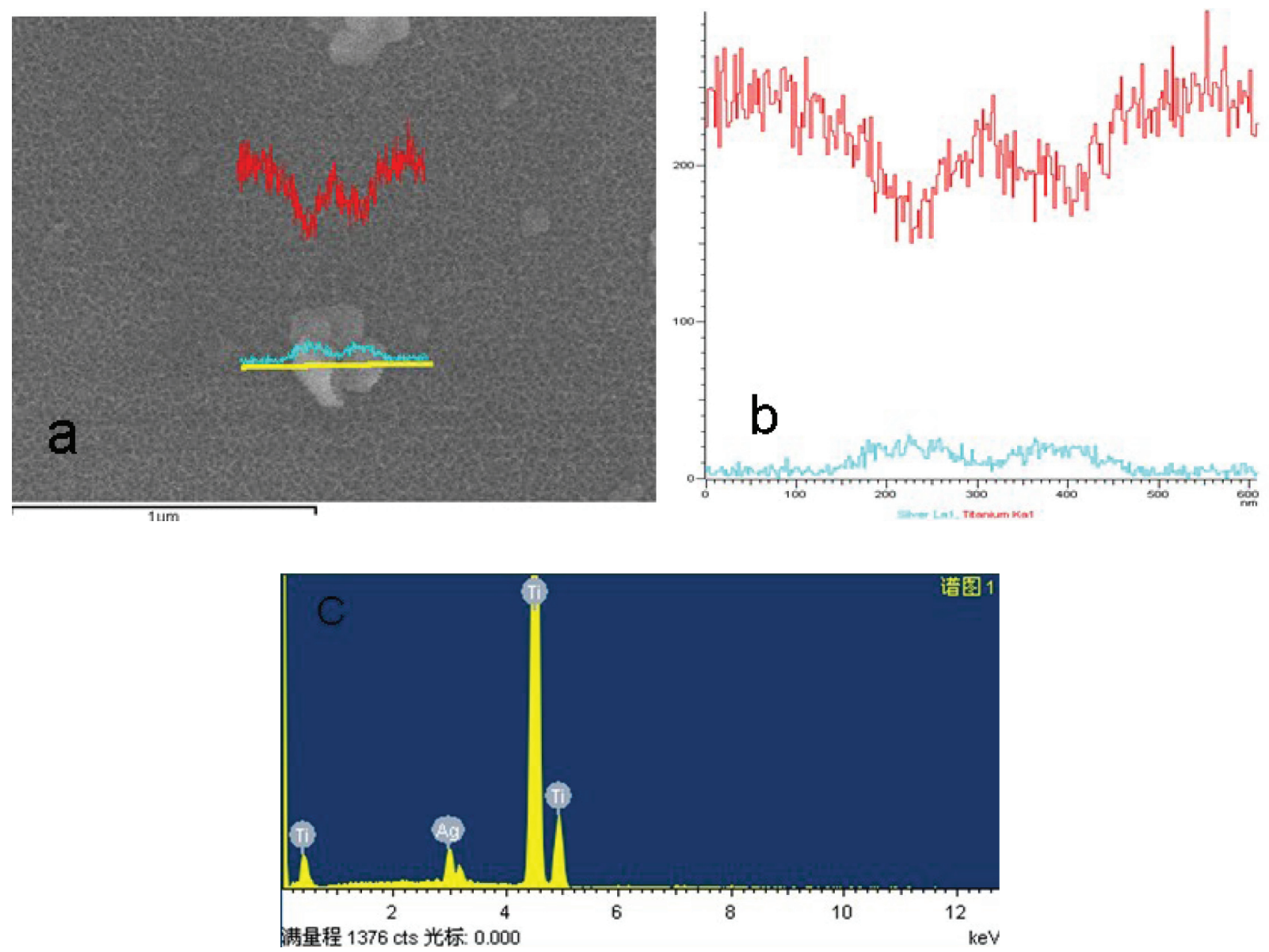

Figure 3 Line scanning of EDS image of the particle on the Ti-nAg surface.

Notes: The green line stands for $\mathrm{Ag}$ and the red line stands for titanium.

Abbreviations: EDS, energy-dispersive spectroscopy; $\mathrm{Ti}$-nAg, silver nanoparticle-modified titanium.

silver has a very low rate of dissolution in an aqueous environment, ${ }^{23}$ it is possible that the silver dissociated from the titanium surface did not reach a concentration sufficient to inhibit bacterial growth. This observation is consistent with the study of Ahearn and colleagues, in which they found negligible zones of inhibition when testing the release of ions from ion beam with a silver coating. ${ }^{24}$

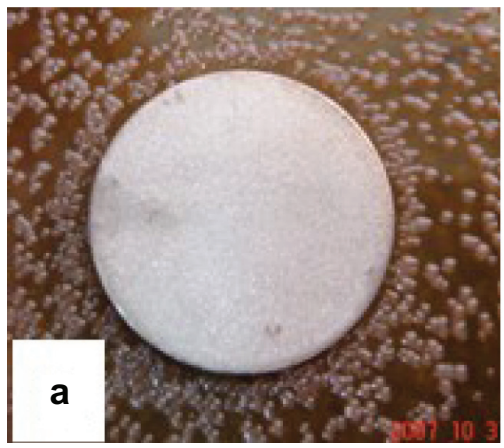

Figure 4 Photographs showing the Zol tests for Ti-nAg (a) and Ti-polished (b). Abbreviation: Zol, zone of inhibition.
In contrast, in FAC assay, the Ti-nAg surface exhibited a strong antibacterial property. Following 24-hour incubation of bacteria on Ti-nAg surface, 94\% Staphylococcus aureus and more than $95 \%$ Escherichia coli in the bacteria suspension were killed (Figure 5). Ti-nAg specimens significantly inhibited the growth of both Staphylococcus aureus and Escherichia coli $(P<0.05)$ than Ti-polished specimen.

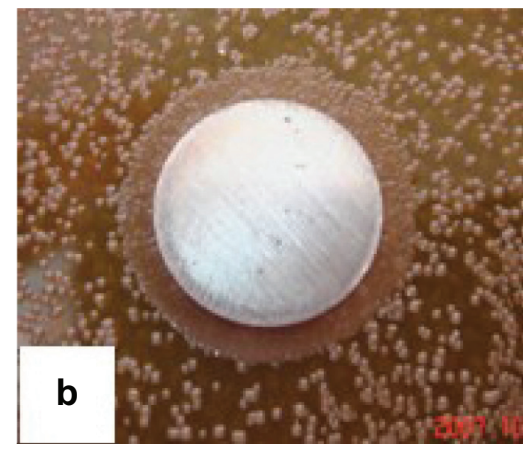


Table I Results of EDS analysis for chemical elements of the $\mathrm{Ti}-\mathrm{nAg}$ surface

\begin{tabular}{lll}
\hline Element & w\% & at\% \\
\hline $\mathrm{Ti}$ & 90.90 & 95.74 \\
$\mathrm{Ag}$ & 9.10 & 4.26 \\
total & 100.00 & 100.00 \\
\hline
\end{tabular}

Notes: w\%, weight percentage; at\%, atomic percent.

Abbreviations: EDS, energy-dispersive spectroscopy; $\mathrm{Ti}$-nAg, silver nanoparticlemodified titanium.

The discrepancy between ZoI and FAC tests may be due to the difference of the antibacterial mechanism. The former relied on leaching of the silver ions from the surface, whereas the latter mediated an inhibitory effect by direct contact.

The SEM examination of anti-adhesive test showed that there were much less bacteria adherent to Ti-nAg surface than to the control titanium surface (Figure 6). This was due to the direct contact inhibition and the anti-adhesive properties of the Ti-nAg surface. Therefore it is suggested that the Ti-nAg surface reduces the risk of bacterial colonization.
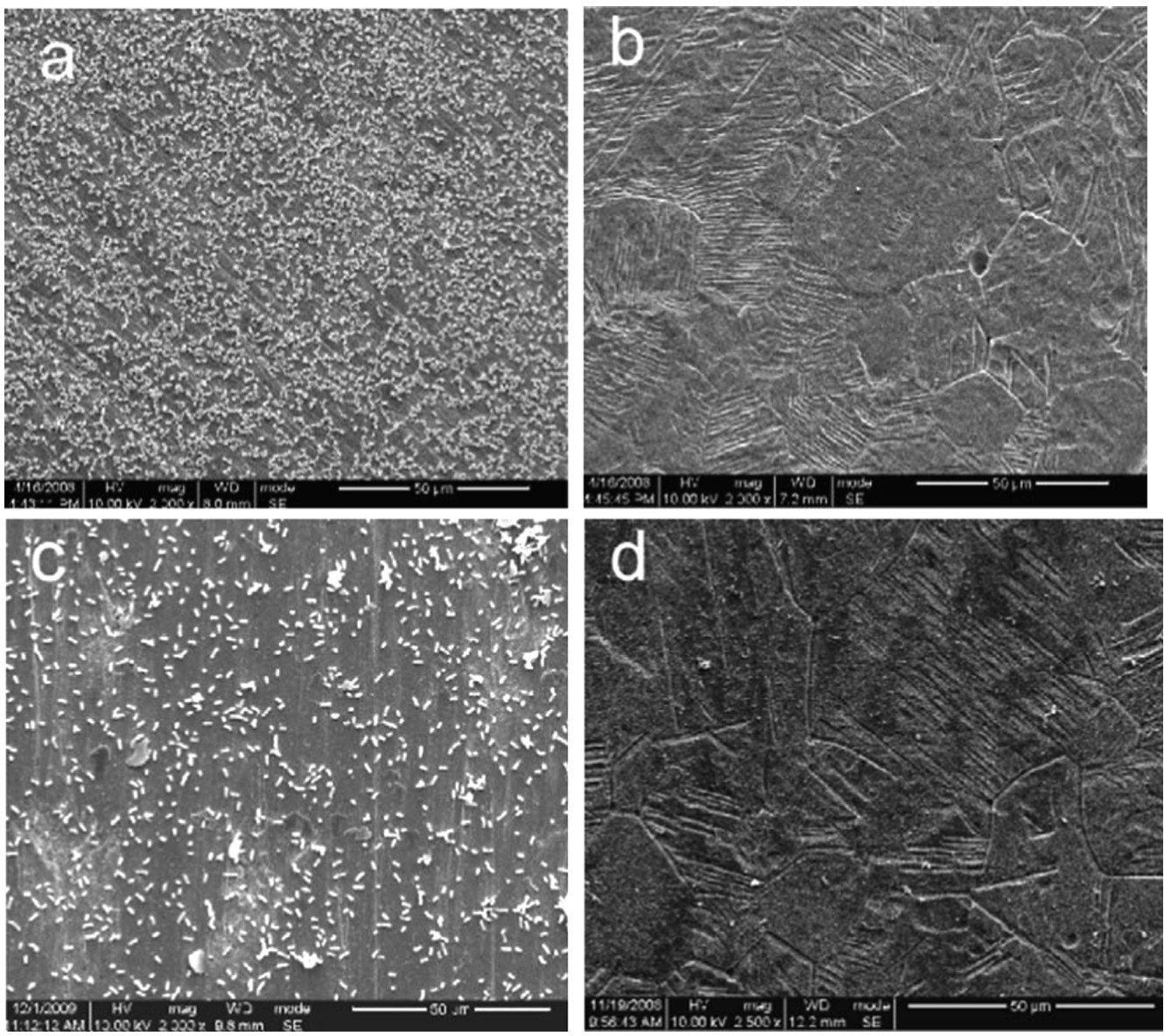

Figure 6 SEM images of the Ti-polished (a and c) and Ti-nAg (b and d) surfaces after incubation of Staphylococcus aureus (a and b) and Escherichia coli (c and d). Notes: Magnification $\times 2000$, working distance $8000 \mu \mathrm{m}$.

Abbreviation: SEM, scanning electron microscopy.

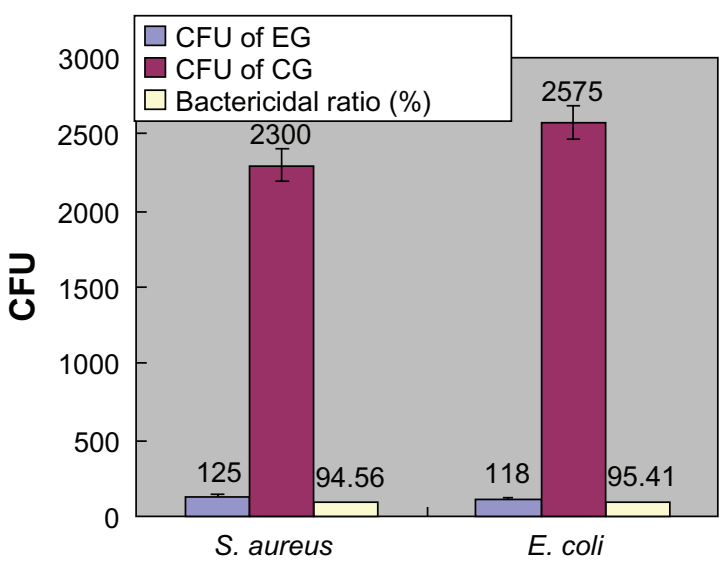

Figure 5 Counts of CFU (Mean \pm SD) and bactericidal ratio in FAC test. Abbreviations: $\mathrm{CFU}$, colony-forming unit; $\mathrm{CG}$, control group; EG, experimental group; SD, standard deviation; S. aureus, Staphylococcus aureus; E. coli, Escherichia coli.

\section{Conclusion}

In the present study, we prepared a silver nanoparticlemodified titanium surface using a silanization method. The SEM images show that a small amount of silver nanoparticles were successfully coated on the titanium surface. 
The diameter of silver nanoparticles ranged from ten to several hundred nanometers. EDS analysis of the surface showed that atomic percentage of silver was only $4.26 \%$. FAC assays and anti-adhesive testing showed that the Ti-nAg surface had remarkable antibacterial and anti-adhesive activities towards Staphylococcus aureus and Escherichia coli. These data suggest that silver nanoparticle-modified titanium is a promising material with the antibacterial properties that may be used as an implantable biomaterial.

\section{Disclosures}

The authors report no conflicts of interest in this work.

\section{References}

1. Schierholz JM, Morsczeck N, Brenner DP, et al. Special aspects of implant-associated infection in orthopaedic surgery. Der Orthopade. 2004;33:397-404

2. Esposito M, Hirsch J, Lekholm U, Thomsen P. Biological factors contributing to failures of osseointegrated oral implants.(II). Ktiopathogenesis. Eur I Oral Sci. 1998;106:721-764.

3. Gristina AG. Biomaterial-centered infection: Microbial adhesion versus tissue integration. Science. 1987;237:1588-1595.

4. Meredith DO, Eschbach L, Riehle MO, Curtis ASG, Richards RG. Human fibroblast reactions to standard and electropolished titanium and Ti-6Al-7Nb, and electropolished stainless steel. J Biomed Mater Res. 2005;75(A):541-555.

5. Bacte-Koerner RJ, Butterworth LA, Mayer IV, et al. Bacterial adhesion to titanium-oxy-nitride (TiNOX) coatings with different resistivities: a novel approach for the development of biomaterials. Biomaterials. 2002;23(14):2835-2840.

6. Crede KSF. Die Verhutung der Augenentzundung der Neugeborenen, der haufigsten und wuchtigsten Ursache der Blindheit. Berlin: A. Hirschwald; 1894.

7. Qing Ling Feng, Taik Nam Kim, Jing Wu, Eui Seo Park, Jong Ock Kim. Antibacterial effects of Ag-HAp thin films on alumina substrates. Thin Solid Films. 1998;335:214-219.

8. Feng QL, Kim TN, Wu J, et al. Antibacterial effects of Ag-HAp thin films on alumina substrates. Thin Solid Films. 1998;335:214-219.

9. Kawahara K, Tsuruda K, Morishita M, Uchida M. Antibacterial effect of silver-zeolite on oral bacteria under anaerobic conditions. 2000;16:452-455.
10. Alt V, Bechert T, Steinrücke P, et al. An in vitro assessment of the antibacterial properties and cytotoxicity of nanoparticulate silver bone cement. Biomaterials. 2004;25:4383-4391.

11. Lee HY, Park HK, Lee YM, Kim K, Park SB. A practical procedure for producing silver nanocoated fabric and its antibacterial evaluation for biomedical applications. Chem Commun. 2007;28:2959-2961.

12. Kvitek L, Panacek A, Soukupova J, Kolar M, Vecerova R, Prucek R, et al. Effect of surfactants and polymers on stability and antibacterial activity of silver nanoparticles (NPs). J Phys Chem C. 2008;112: $5825-5834$.

13. Arumugam SK, Sastry TP, Sreedhar SB, Mandal AS. One step synthesis of silver nanorods by autoreduction of aqueous silver ions with hydroxyapatite: an inorganic-inorganic hybrid nanocomposite. J Biomed Mater Res. 2007;80(A):391-398.

14. Min Y, Akulut M, Kristairsen K, Golan Y, Israelachvili J. The role of interparticle and external forces in nanoparticle assembly. Nat Mater. 2008; 7:527-538.

15. Zheng J, Hua Y, Xinjun L, Shanqing Z. Enhanced photocatalytic activity of $\mathrm{TiO}_{2}$ nano-structured thin film with a silver hierarchical configuration. Appl Surf Sci. 2008;254(6):1630-1635.

16. Aslan K, Lakowicz JR. Rapid deposition of triangular silver nanoplates on planar surfaces: application to metal-enhanced fluorescence. J Phys Chem B. 2005;109(13):6247-6251.

17. Geddes CD, Cao H, Gryczynski I, Gryczynski Z, Fang J, Lakowicz JR. Metal-enhanced fluorescence (MEF) due to silver colloids on a planar surface: potential applications of indocyanine green to in vivo imaging. J Phys Chem A. 2003;107(18):3443-3449.

18. Henglein A, Giersig M. Formation of colloidal silver nanoparticles: capping action of citrate. J Phys Chem B. 1999;103(44):9533-9539.

19. Aslan K, Lakowicz JR, and Geddes CD. Rapid deposition of triangular silver nanoplates on planar surfaces: application to metal-enhanced. J Phys Chem. 2005;109(13):6247-6251.

20. Morones JR, Elechiguerra JL, Camacho A, Ramirez JT. The bactericidal effect of silver nanoparticles. Nanotechnology. 2005;16:2346-2353.

21. Song HY, Ko KK, Oh LH, Lee BT. Fabrication of silver nanoparticles and their antimicrobial mechanisms. Eur Cells Mater. 2006; 11(Suppl 1):58.

22. Gristina AG, Costerton JW. Bacterial adherence to bio-materials and tissue. The significance of its role in clinical sepsis. J Bone Joint Surg. 1985;67(2):264-273.

23. Sambhy V, MacBride MM, Peterson BR, Sen A. Silver bromide nanoparticle/polymer composites: dual action tunable antimicrobial materials. J Am Chem Soc. 2006;128(30):9798-9808.

24. Ahearn D, May L, Gabriel M. Adherence of organisms to silver-coated surfaces. J Ind Microbiol. 1995;15(4):372-376.
International Journal of Nanomedicine

\section{Publish your work in this journal}

The International Journal of Nanomedicine is an international, peerreviewed journal focusing on the application of nanotechnology in diagnostics, therapeutics, and drug delivery systems throughout the biomedical field. This journal is indexed on PubMed Central, MedLine, CAS, SciSearch $®$, Current Contents ${ } /$ Clinical Medicine,

\section{Dovepress}

Journal Citation Reports/Science Edition, EMBase, Scopus and the Elsevier Bibliographic databases. The manuscript management system is completely online and includes a very quick and fair peer-review system, which is all easy to use. Visit http://www.dovepress.com/ testimonials.php to read real quotes from published authors. 